
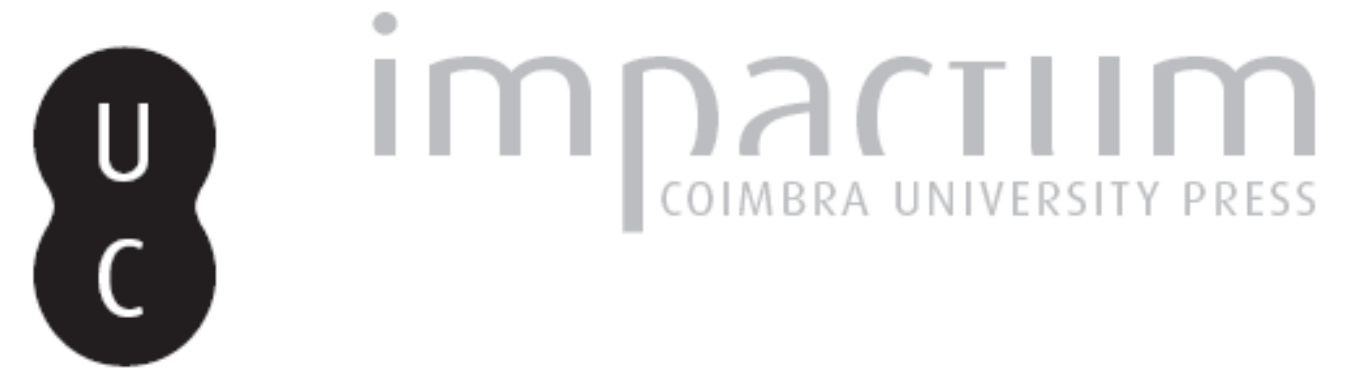

\title{
Límites de la historia social clásica de la pobreza y la asistencia en España
}

\section{Autor(es): $\quad$ Carasa, Pedro}

Publicado por: Centro de História da Sociedade e da Cultura

URL persistente:

URI:http://hdl.handle.net/10316.2/39536

DOI:

DOI:http://dx.doi.org/10.14195/1645-2259_10-2_10

Accessed : $\quad$ 26-Apr-2023 12:25:17

A navegação consulta e descarregamento dos títulos inseridos nas Bibliotecas Digitais UC Digitalis, UC Pombalina e UC Impactum, pressupõem a aceitação plena e sem reservas dos Termos e Condições de Uso destas Bibliotecas Digitais, disponíveis em https://digitalis.uc.pt/pt-pt/termos.

Conforme exposto nos referidos Termos e Condições de Uso, o descarregamento de títulos de acesso restrito requer uma licença válida de autorização devendo o utilizador aceder ao(s) documento(s) a partir de um endereço de IP da instituição detentora da supramencionada licença.

Ao utilizador é apenas permitido o descarregamento para uso pessoal, pelo que o emprego do(s) título(s) descarregado(s) para outro fim, designadamente comercial, carece de autorização do respetivo autor ou editor da obra.

Na medida em que todas as obras da UC Digitalis se encontram protegidas pelo Código do Direito de Autor e Direitos Conexos e demais legislação aplicável, toda a cópia, parcial ou total, deste documento, nos casos em que é legalmente admitida, deverá conter ou fazer-se acompanhar por este aviso.

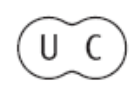




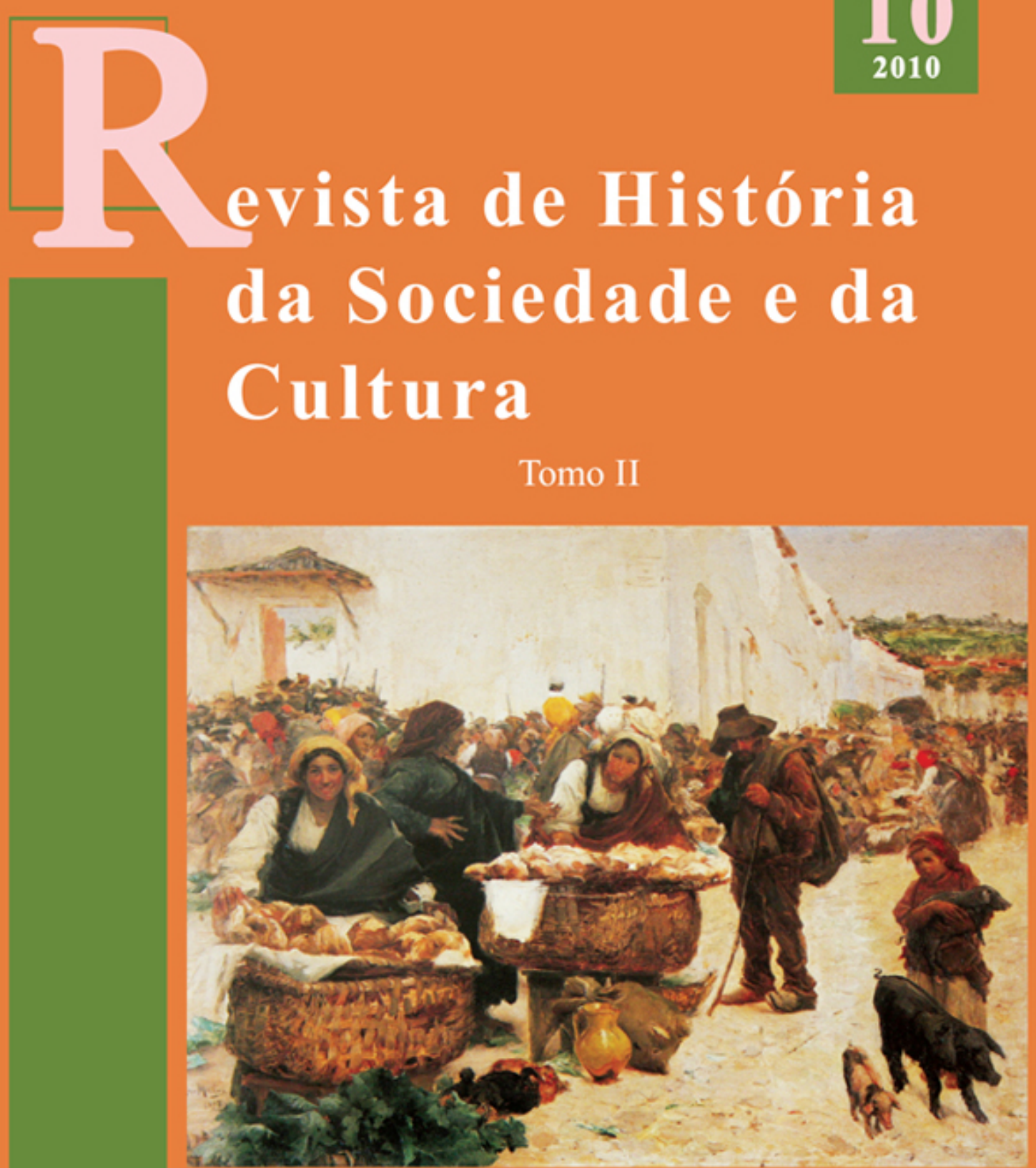

Centro de História da Sociedade e da Cultura Universidade de Coimbra

Coimbra 


\title{
Límites de la historia social clásica de la pobreza y la asistencia en España
}

\author{
Pedro Carasa \\ Universidad de Valladolid \\ carasa@fyl.uva.es \\ Texto recebido em/ Text submitted on: 28/02/2010 \\ Texto aprovado em/ Text approved on: 20/05/2010
}

\section{Resumo/Abstract:}

No contexto das quatro etapas da historiografia espanhola sobre pobreza e assistência, analisam-se os objectivos que nortearam cada geração de historiadores. Estes estiveram sempre vinculados aos sistemas gerais de cada momento histórico e dependentes da ideologia de cada período historiográfico, desde o providencialismo, até ao pós-modernismo, passando pelo liberalismo e o materialismo histórico. As suas limitações mais gritantes foram impostas pela racionalidade clássica-patriarcal aplicada à economia e à sociedade, por se centrar nos sistemas e não nas pessoas, por se esgotar no método dialéctico e por se apoiar nos sujeitos abstractos, colectivos e institucionais dos privilegiados, a Coroa, o Estado ou a classe social. O resultado foi o fraco protagonismo do sujeito consciente e a desumanização da história social.

In the context of the four stages of Spanish historiography on poverty and aid, this paper analyses the purposes which have driven every generation of historians. These are the underlying purposes of the global systems of every historical moment, which depend on the ideology of each stage of historiography, from providentialism to post-modernism, including liberalism and historical materialism. Its strongest constraints were imposed by the classical and patriarchal reasoning applied to the economy and society, as it is system and not people-oriented, it is restricted to the dialectic method, and focuses on abstract, collective and institutional subjects of the favoured, the Crown, the State or social class. The final effect was the weak presence of the cognisant individual and the dehumanization of social history.

Palavras chave/Keywords:

Historiografia; Pobreza e assistência; Materialismo; História cultural.

Historiography; Poverty and aid; Materialism; Cultural history. 


\section{Etapas de la historiografía de la asistencia y la pobreza}

La historiografía de la pobreza y la asistencia en España ${ }^{1}$ se periodiza en cuatro etapas, la última aún inconclusa. En la primera, durante los años cincuenta y sesenta, esta historia padeció una infancia de tono pobre y apologético, en que, por parte de escasos historiadores profesionales y de una nutrida tropa de eruditos locales, se relataban las grandes generosidades y desinteresadas fundaciones de los miembros más egregios de la sociedad del pasado, movidos por el sentido del deber ético-religioso. La segunda etapa, que podríamos denominar de juventud, se desarrolló durante los años setenta y primeros ochenta, y corrió a cargo de una abundante cantidad de tesinas de licenciatura y tesis doctorales, ya en el marco universitario. Éstas resultaban casi todas cortadas por el mismo patrón, de naturaleza meramente institucionalistas, estudiaban las características económicas, administrativas y asistenciales de las instituciones, habitualmente locales, aisladas del resto del equipo asistencial y por lo común desincardinadas del entorno social, económico y mental. La tercera etapa, que podemos llamar adulta, se vive durante los años ochenta y sigue vigente hasta principios del siglo XXI, protagonizada por una segunda generación de tesis. Trataron de innovar la metodología institucionalista y lograron enriquecerla, fundamentándola más en el pauperismo que en la asistencia y basándola en una triple interacción entre sociedad-pobreza-beneficencia, de manera que el objetivo básico aspiraba a desentrañar las relaciones del pauperismo con la sociedad, de la asistencia con el pauperismo y de la sociedad con la asistencia. Este último planteamiento se realizó desde una perspectiva bastante estructuralista aún, de acuerdo con los paradigmas clásicos de la historia social y de la historia económica. La cuarta etapa está organizándose desde hace una década y aún no ha llegado a su plena definición. Trata de virar la perspectiva de la pobreza y la asistencia hacia abajo, pretende cambiar el sujeto del pauperismo por los comportamientos, actitudes y roles del pobre, fijarse más en los asistentes y sus representaciones que en el fenómeno institucional de

1 CARASA SOTO, Pedro - La pobreza y la asistencia en la historiografía española contemporánea. Hispania; L/3, 76 (1990) 1475-1503. 
la asistencia. Orienta el estudio en la dirección cultural y trata de escapar de las obsesiones clásicas de la historia económica y de la vieja historia social.

Es verdad que esta historiografía ${ }^{2}$ ha tenido importantes defectos. En el período segundo de los años setenta, las limitaciones eran grandes, puesto que no fue más allá de una descripción institucional, que no era más rica que otras descripciones políticas o administrativas, y dejaba escapar las más importantes cuestiones que planteaba el fenómeno de los pobres en aquellas sociedades. Tampoco descubría cuáles eran los objetivos de los asistentes, ni siquiera alcanzaba a explicar todos los motores que movían la máquina asistencial. Incluso la tercera etapa, aunque había superado estas limitaciones, se formulaba nuevas preguntas y había llegado a ofrecer interesantes respuestas, se encontraba aún limitada por serios defectos. Éstos $^{3}$ podrían concretarse en un agobiante estructuralismo, en una atención insistente a los tiempos largos y desprecio de los cambios sociales más rápidos, en interpretaciones monolíticamente economicistas, demasiado mecanicistas y conflictivistas, y en olvidos tan decisivos como pueden ser los aspectos culturales, mentales, de religiosidad o de sociabilidad.

Pero la inercia de esta tercera etapa en la historiografía española ha sido demasiado pesada, y ha lastrado seriamente la capacidad de innovary avanzar hacia los planteamientos de la cuarta etapa cultural. Sobre este lastre nos ilustra el congreso de la Asociación de Historia Social celebrado en 2008, que planteó aun la pobreza y la asistencia como meros elementos marginales del sistema productivo y agregados espurios de la estructura social. Su programa era institucional y cuantitativo, centrado en los sistemas amenazados: "Pobreza, delito y desviación (tipologías, desarrollo y significado en la estructura social). Mendicidad, delincuencia y locura como formas de marginación. Mecanismos de control social (cárceles, galeras y presidios; sistemas de penalidad; asilos, reformatorios, campos de concentración, instituciones punitivas, sistemas y cuerpos represivos). Discursos sobre lo marginal (concepto de caridad, piedad o beneficencia; noción y sistemas de asistencia social; integración y control de la marginalidad; sistemas de

2 ESTEBAN DE VEGA, Mariano (Ed.) - Pobreza, beneficencia y política social, Ayer, 25 (1997).

3 CARASA SOTO, Pedro - La Historia y los pobres: De las bienaventuranzas a la marginación. Historia Social, 13 (1992) 77-99. 
previsión social y socorro). Trabajo y oficio, etnicidad, edad, sexo y género en la marginalidad (paro y estructura social, asociaciones étnicas y de emigrantes, ancianidad e infancia como formas de marginación, sexualidad desviada, discriminación y exclusión de género)"4. En definitiva, todo un panorama estructuralista propio de la tercera etapa de los años ochenta, aferrado a la perspectiva aérea del sistema, del orden social, del control y la represión. Cuando se acerca a los nuevos elementos propios de la cuarta etapa, los discursos, el sexo, el género, el oficio, no menciona la familia ni se detiene en aspectos culturales, lo hace desde la vieja perspectiva de la marginación y la exclusión con relación a los sistemas vigentes.

En estas líneas pretendemos reflexionar sobre estas limitaciones que la historiografía clásica ha mostrado para descubrir el significado social de los pobres y sobre la incapacidad que ha tenido para ahondar en las actitudes y comportamientos de los asistentes, más allá de los fenómenos colectivos y de las estructuras institucionales 5 .

\section{Significados que la historia social clásica ha atribuido a la pobreza y a la asistencia}

El primer objetivo de la historiografía tradicional fue ensalzar la obra caritativa y religiosa de personas e instituciones. Todos los significados que han perseguido los historiadores de la pobreza y la asistencia en España, todos los objetivos concretos que han movido a la historiografía clásica han coincidido en situarse en la teleología propia de los sistemas generales dominantes en cada momento. Nadie consideraba el funcionamiento de un tipo de economía diferente del que practicaban los burgueses actores del sistema capitalista, no había espacio para admitir economías alternativas,

4 Santiago CASTILLO - La historia social en España: actualidad y perspectivas. Madrid: Siglo XXI, 1991.

5 En CARASA SOTO, Pedro - La historia y los pobres: de las bienaventuranzas a la marginación. Historia Social, 13 (199) 77-100, inicié estas reflexiones que de alguna manera significaban una primera revisión de mi propia tesis doctoral P.CARASA - Pauperismo y Revolución Burguesa. Burgos, 1750 -1900. Valladolid: Universidad de Valladolid, 1987. 
familiar, de subsistencia, de supervivencia, o del cuidado ${ }^{6}$. Con ese instrumento de análisis siempre quedaba fuera del alcance del historiador el asunto de la subsistencia de los pobres y el papel que la resolución de sus problemas personales y sociales jugaba en la sostenibilidad del sistema general.

Los cambios de significados atribuidos por la historiografía clásica de la asistencia se han referido a los elementos vertebradores del sistema general feudal primero y luego capitalista. Los iniciadores de estos temas, en la primera etapa de la historiografía española arriba mencionada, eran historiadores del ámbito eclesiástico o entorno clerical, que entendían los estudios de pobreza y caridad como medios de hagiografía religiosa y de historia eclesiástica ${ }^{7}$. Casi deudores de la misma mentalidad sacralizada tardo feudal, manejaban la historia de la pobreza y la asistencia como instrumentos útiles para ensalzar la obra caritativa de personajes e instituciones, para abonar la acción social de la Iglesia histórica. En la etapa siguiente los institucionalistas y positivistas interpretaron la pobreza y la asistencia como productos lógicos bien insertos en los organigramas administrativos y como subproductos de la construcción administrativa del Estado liberal. Serán más tarde los marxistas los que encajen el análisis de la pobreza en el objetivo general de subrayar las contradicciones del sistema burgués capitalista y de

6 DURÁN, María Angeles - La contribución del trabajo no remunerado a la economía española: alternativas metodológicas. Madrid: Instituto de la Mujer, 2000. AGULLÓ, Mercedes - Mujeres, cuidados y bienestar social: el apoyo informal a la infancia y a la vejez. Madrid: Ministerios de Trabajo y Asuntos Sociales, Instituto de la Mujer, 2002. TORONJO, Angela María - Cuidador formal frente al cuidador informal. Barcelona: Gerokomos, 2001; ÚBEDA, Ignacio; ROCA, Manuel; GARCÍA VIÑETS, Lourdes - Presente y futuro de los cuidados informales. Barcelona: Enfermería Clínica, 1997; DOMÍNGUEZ-ALCÓN, Carmen - Cuidado informal, redes de apoyo y politicas de vejez. Madrid: Index Enfermería, 1998; MONTGOMERY, Rhonda J. V. - The Family role in the context of long-term care. Aging Health, 1999; INSERSO - Cuidados en la Vejez. El apoyo informal. Madrid: Ministerio de Asuntos Sociales, 1995. SETIÉN, María Luisa - Género y cuidados a las personas en el ámbito doméstico. Bilbao: Inguruak, 1998. HARRINGTON, Margaret M. - Care Work: gender, class, and the welfare state. New York: Routledge, 2000. NAVARRO, Vinçent Bienestar insuficiente, democracia incompleta. Sobre lo que no se habla en nuestro país. Barcelona: Anagrama, 2002. LA PARRA, Daniel - Contribución de las mujeres y los hogares más pobres a la producción de cuidados de salud informales. Madrid: Gaceta Sanitaria, 2001.

7 JIMÉNEZ SALAS, María - Historia de la Caridad en la España Moderna, Madrid, 1957; RUMEU DE ARMAS, Antonio - Historia de la Previsión Social en España. Cofradías, Gremios, Hermandades y Montepíos. Madrid, 1970. 
poner de relieve las tensiones y conflictos de una sociedad en perpetua lucha de clases e intereses materiales ${ }^{8}$. Variaban los objetivos historiográficos, pero no cambiaba la perspectiva desde arriba, desde la atalaya superior de los presupuestos y los discursos propios del sistema de cada momento. No sólo en el sentido de posicionarse en la lógica del sistema socio-económico histórico, sino también en el sentido de seguir los axiomas de la ideología dominante en la historiografía del momento de cada historiador.

La segunda búsqueda de la historiografía erudita se centró en la identidad local, por el prurito de realzar el pasado de la propia localidad. Los primeros eruditos locales, unos eclesiásticos y otros imbuidos de un sentimiento religioso que lo impregnaba todo, buscaron en los análisis de la pobreza y la asistencia unos signos de identidad local y una erudición que contribuía al prurito de conocer el pasado y realzar la propia localidad, ciudad o provincia ${ }^{9}$. Desde el siglo XIX se realizaron estudios legales e institucionales de la beneficencia ${ }^{10}$, pero estos estudios positivistas se generalizaron en los sesenta y setenta del siglo XX. Particularmente en los ámbitos hostiles al materialismo ${ }^{11}$, muy activo entonces en la universidad española, se activó una historia social orientada sólo a la reconstrucción institucional de la gestión

8 Nuestra tesis, Pauperismo y Revolución Burguesa, cit., fue pionera en este sentido, sostuvimos esta hipótesis con mayor contundencia en BERGALLI, Roberto y MARI, Enrique E. (coord) - Historia ideológica del control social, Barcelona: PPU, 1989. CARASA, Pedro Metodología del estudio del pauperismo en el contexto de la Revolución Burguesa española, en CASTILLO, Santiago (coord.) - La Historia Social en España. Actualidad y perspectivas. Madrid, 1991, pp. 359-384. Casi todas las ponencias y comunicaciones referidas a la pobreza y asistencia en dicho congreso iban en esta dirección. En la misma línea influyeron autores como SERNA ALONSO, Justo - Presos y pobres en la España del XIX. La determinación social de la marginación, Barcelona: PPU, 1988. En varias comunidades autónomas aparecieron estudios en esta misma clave interpretativa: ALVAREZ SANTALÓ, Carlos; VALENZUELA, José; LÓPEZ MORA, Antonio; CARMONA, Juan: MARCOS, Alberto; ESTEBAN, Mariano; SOUBEYROUX, Jacques; CARBONELL, Montserrat; GRACIA, Juan.

9 Casi todas las provincias españolas disponen de varios estudios en revistas de estudios locales sobre las obras de caridad y los grandes benefactores.

${ }^{10}$ HERNÁNDEZ IGLESIAS, Fermín - La Beneficencia en España. Madrid: Establecimientos Tipográficos de Manuel Minuesa, 1876. A.BALBÍN DE UNQUERA - Manual de Beneficencia. Madrid, 1886. BALBÍN DE UNQUERA, Antonio; ARIAS MIRANDA, José - Reseña histórica de la beneficencia española; ARENAL, Concepción - La beneficencia, la filantropía y la caridad: memoria premiada por la Real Academia de Ciencias Morales y Políticas... Madrid: Imprenta del Colegio de sordo-mudos y de ciegos, 1861.

${ }^{11}$ Se editaron estudios universitarios redactados por eclesiásticos, con cierto carácter anti-materialista, como LLORCA, Bernardino; GARCÍA VILLOSLADA, Ricardo; 
de la pobreza y la asistencia, desde una perspectiva meramente positivista y descriptiva. Así trataban indirectamente de demostrar que no debían buscarse debajo de la pobreza y la asistencia lecturas interesadas, ni providencialistas ni materialistas, sino sencillamente actos objetivos de caridad estamental, de filantropía ilustrada o de beneficencia liberal.

A continuación, la historiografía liberal trató de demostrar el progreso y los aspectos positivos del liberalismo. En los años sesenta, la historia social se abrió al liberalismo, pobreza y asistencia fueron consideradas como mecanismos de seguridad imprescindibles en la reproducción imparable del progreso liberal, y al propio tiempo como un medio de valorar los aspectos positivos del liberalismo al descubrir en su seno una política social. En este momento, la pobreza y la asistencia se comprenden referidas a las instituciones del Estado liberal ${ }^{12}$. Dominaba entonces la historia cuantitativa, muchos historiadores abordaron la pobreza y la asistencia como un complemento de la descripción demográfica y cliométrica de la sociedad, contando pobres y asistidos, buscando enfermedades, afinando tasas de mortalidad, infantil, de expósitos, hospitalaria ${ }^{13}$. Esta vinculación de la pobreza/asistencia con el Estado más que con las demandas sociales ya se había planteado en el debate sobre el reformismo social liderado por los regeneracionistas de principios del XX. La cuestión que les interesaba era si el Estado tenía o no competencias sociales, más que si la sociedad tenía o no necesidades. Desde entonces, las políticas sociales han sido vistas sólo como derivaciones colaterales del poder del Estado desde arriba, no como demandas nacidas abajo desde los desequilibrios de la sociedad. En este mismo contexto, los medios historiográficos afines a las posiciones de la Iglesia insistieron en el tratamiento de la pobreza ofrecido por el

GARCÍA ORO, José; CÁRCEL ORTÍ, Vicente; PALOMARES, Jesús María; REVUELTA GONZÁLEZ, Manuel.

${ }^{12}$ Miguel ARTOLA inició esta interpretación liberal sentenciando con demasiada rotundidad que en el XIX se realizó el traspaso del encargo asistencial de la Iglesia al Estado.

${ }^{13}$ LÓPEZ ALONSO, Carmen - La pobreza en la España medieval. Madrid: Ministerio de $\mathrm{T}^{\mathrm{o}}$ y Seguridad Social, 1986. MAZA ZORRILLA, Elena - Pobreza y asistencia social en España, Valladolid: Universidad de Valladolid, 1987. VV.AA. - De la beneficencia al bienestar social. Cuatro siglos de acción social. Madrid: Consejo General de Colegios Oficiales de Diplomados en Trabajo Social y Asistentes Sociales, 1988. VV.AA. - Historia de la acción social pública en España. Beneficencia y previsión. Madrid: Centro de Publicaciones del Ministerio de Trabajo y Seguridad Social, 1990. 
catolicismo social, como defensa de la Iglesia, como lenitivo contra la agresión anticlerical de anarquistas y socialistas.

Ha sido poderoso el impacto del debate sobre la cuestión social en el planteamiento de la historia social clásica. Las reformas liberales de la economía y la sociedad produjeron fuertes desajustes sociales que condicionaron históricamente la manera de concebir y tratar las cuestiones sociales. El desequilibrio en el reparto de la riqueza, la aparición del pauperismo, la falta de acceso a la felicidad de los ciudadanos, provocaron insistencias alternativas en los contrapuestos elementos que formaban parte del problema histórico que debía resolverse, y de la misma manera, la solución del pauperismo se percibió desde planteamientos contradictorios que produjeron políticas sociales enfrentadas. Podían ser sacralizadas o secularizadas - según que los actores y sus intereses fueran espirituales o materiales -, particulares o generales - según procedieran de las fuerzas privadas e individuales desde abajo o de las fuerzas colectivas y oficiales desde arriba -, pacificadoras o conflictivas - según tendieran a la mutua armonía conservadora o a la recíproca destrucción radical -, privadas o públicas - según buscaran la solución en el libre desarrollo en competencia individual o en la corrección interventora oficial y colectiva -, religiosas o estatales - según encontraran la legitimidad de la solución en la religión y la moral, o en la política y la ley. De acuerdo con una u otra opción, cambiaba radicalmente el resultado, o exigían dejarlo todo a la iniciativa particular o reclamaban la intervención pública, agradecían la asistencia como un regalo gratuito o la reclamaban como un derecho exigible. Cuando se impuso la segunda solución de las dos alternativas, el reformismo social entendió el problema del pauperismo y la asistencia inextricablemente unido a las concepciones generales del sistema económico y del organismo social. Al tiempo, se alejaban de los problemas personales, se desentendía de los sentimientos religiosos y se concebía fuera del ámbito de lo privado y lo particular, es decir, se había sentenciado el paradigma estructural y sistémico en el que debía comprenderse el problema de la pobreza y la asistencia.

La primera solución de tipo armonizador propia de la cultura social del antiguo régimen apelaba a su imaginario individualista y a la sacralización de las relaciones de salvación. Éstas establecían que la finalidad soteriológica de cada uno exigía armonizar la contraposición de intereses en la última 
meta salvadora: los ricos salvaban su alma dando limosna y socorriendo a los pobres, y éstos conseguían su salvación aceptando resignadamente esta ayuda y su situación; los ricos invertían así su patrimonio en renta espiritual y los pobres se beneficiaban de esta inversión sobrenatural alcanzando el único negocio importante, que era salvar el alma. La finalidad armonizadora de los conservadores, que estimaban más rentable socialmente curar con la beneficencia que prevenir con la previsión social, dejaba en manos de la iniciativa particular la solución del problema. En el fondo acataban la teoría sacralizadora del sistema, que consideraba la existencia de la pobreza como necesaria para que pudiera ejercerse la caridad; la igualdad social sólo se alcanzaba en el más allá, nunca era presentada como un objetivo alcanzable en este mundo ${ }^{14}$. Una vinculación, pues, a un sistema superior de legitimación.

Otra segunda solución, también deudora de otro sistema superior legitimador, fue la propuesta por la cultura social del primer liberalismo ${ }^{15}$. Se desentendió de los desequilibrios sociales introducidos por la industrialización, convencido de que la mano invisible reequilibraría las cosas. La teleología de la fe en el progreso no sólo era económica, era también social, porque la prosperidad general era también causa de una felicidad general. Incluso cuando el problema se plantea en ámbitos más avanzados, como en Inglaterra donde nacen precoces cuestiones sociales, la solución apunta hacia el paternalismo filantrópico que propone una asistencia informal y voluntarista. Este tránsito que permitió pasar de la caridad a la beneficencia liberal se produjo lentamente en España, donde la solución estuvo casi siempre y mayoritariamente en manos de las fuerzas sociales de los ayuntamientos, que actuaron como sujetos particulares manejando recursos privados municipalizados. Esta situación, que en buena parte de

${ }^{14}$ CARASA SOTO, Pedro - La revolución nacional asistencial durante el primer Franquismo: El Auxilio Social, 1937-1945. Historia Contemporánea, 16 (1997) 89-140.

${ }^{15}$ CARASA SOTO, Pedro - Los peligros de la pobreza, los valores del liberalismo y las soluciones asistenciales burguesas, en Homenaje al Pfr. Artola. Crisis del Antiguo Régimen y Revolución Liberal. Economía y Sociedad. Madrid, 1993; CARASA SOTO, Pedro - Los valores del liberalismo y las soluciones asistenciales, en El siglo XIX en la España interior. Relaciones de poder y comportamientos políticos. Soria: Universidad Santa Catalina, 1996, p. 115-144. 
Europa cambia en el segundo tercio del siglo XIX, no se inmuta en España hasta bien entrado el siglo XX.

La tercera solución nace de las correcciones de las aristas individuales que formulan los liberales radicales y los demócratas, a medida que avanza el siglo XIX, pero sobre todo se fraguan en la nueva cultura social que genera la industrialización, los movimientos sociales obreros, y las diversas corrientes socialistas. El principio rector de esta cultura es que la solución de los problemas sociales, de la llamada cuestión social, no debe dejarse en manos privadas y debe traspasarse a la iniciativa pública ${ }^{16}$. Es el Estado el que debe intervenir mediante sus recursos fiscales y legales para corregir el problema del reparto de la riqueza en la sociedad, de manera que la asistencia social se convierta en un derecho que asiste al ciudadano y en una obligación que compete al Estado ${ }^{17}$. El presupuesto básico partía de la función redistributiva que se suponía al sistema fiscal del Estado, los recursos obtenidos por los impuestos de los más ricos debían repartirse igualitariamente a la sociedad en forma de servicios, ejerciendo con ello la justicia redistributiva que es inherente a todo Estado de derecho. Pues bien, este escalón evolutivo no se alcanza en España ${ }^{18}$ hasta la segunda mitad del siglo XX, a pesar de que arranca un largo e imperfecto proceso que comienza con el reformismo social en las primeras décadas, retrocede durante la dictadura y no vuelve a retomarse hasta la Transición democrática.

${ }^{16}$ CARASA, Pedro - Beneficencia y Cuestión Social, una contaminación arcaizante. Historia Contemporánea, 29 (2004) 625-670.

${ }^{17}$ CARASA SOTO, Pedro - De la cultura de la protección a la cultura de la previsión, en CASTILLO, Santiago; RUZAFA, Rafael - La previsión social en la historia. Madrid: Siglo XXI, 2009, p. 35-66. CARASA, Pedro - La lenta y tardía conquista de lo público en la construcción del Estado del Bienestar en España, en Congreso de la Asociación de Historia Económica celebrado en Murcia en 2008 sobre El Estado de Bienestar; CARASA SOTO, Pedro - De la cultura de la protección a la cultura de la previsión, ponencia invitada en el VI Congreso de Historia Social, publicada en La previsión social en la Historia, coord. por CASTILLO, Santiago y RUZAFA, Rafael, Vitoria, 2008.

${ }^{18}$ CARASA, Pedro - Lo público y lo privado en la asistencia social española: El triángulo Iglesia, Municipio, Estado, en XXV Encontro da Associaçao Portuguesa de História Económica e Social. Europa e o Mediterráneo: economía e sociedades históricas. Universidade de Evora, 2005; CARASA SOTO, Pedro - Lo público y lo privado en el sistema asistencial: El triángulo Iglesia-Ayuntamiento-Estado en la beneficencia española, en ABREU, Laurinda (ed.) - Asistencia y caridad como estrategias de intervención social: Iglesia, Estado y Comunidad (siglos XV-XX). Bilbao: Universidad del País Vasco, 2007. 
Todo este recorrido histórico es el que ha sedimentado una concepción de la pobreza y la asistencia profundamente enraizada en el sentido de Estado, ha consolidado una manera de entender este problema social como una mera consecuencia de los sistemas económicos, políticos y sociales de carácter general. Desde entonces los científicos sociales perdieron la capacidad de entender las dimensiones humanas, personales o como mucho familiares de este problema.

La dictadura retrocedió más tarde diseñando un sistema asistencial de partido único como recurso de propaganda y movilización política. Impregnados de un profundo ánimo antiliberal, los historiadores sociales del Franquismo en España ahondaron en la misma dirección estatalista, dando una versión extrema de la acción social como instrumento político-social al servicio de un régimen autoritario. La rehabilitación de la política social de la dictadura se orientaba en la dirección de usarla para captar adhesiones políticas al dictador y a su régimen. Plantea la política social de la dictadura como un beneficio que regala el Estado protector, creando así un mecanismo asistencial vinculado al sistema de partido único y utilizado como recurso de propaganda política. Nosotros lo hemos denominado ${ }^{19}$ una "revolución nacional-asistencial", en paralelo a otras revoluciones totalitarias como la nacional-sindicalista, la nacional-católica o la nacional-productiva.

Finalmente, la etapa materialista abordó el análisis del problema social desde la mirada de movimientos sociales, sujetos colectivos y de clase, con planteamientos dialécticos y conflictivos. Esta etapa culmina la sucesión de diferentes significados atribuidos a la pobreza y la asistencia a lo largo de los dos siglos contemporáneos, cierra el proceso del deslizamiento de lo individual hacia lo colectivo, de lo personal hacia lo estatal, de lo particular a lo público, que llena las centurias XIX-XX y alcanza su cenit en la historia social clásica de los setenta. La tendencia hacia lo societario y lo masivo acaba alejando la pobreza del individuo e identificando el pauperismo como un elemento colateral más de la sociedad de masas. De la misma manera, aleja la acción social de los asistentes para centrarla en el Estado y en la clase social, de manera que va desapareciendo el pobre y la asistencia

${ }^{19}$ CARASA SOTO, Pedro - La revolución nacional asistencial durante el primer Franquismo: El Auxilio Social, 1937-1945. Historia Contemporánea, 16 (1997) 89-140. 
como sujetos autónomos de la reflexión histórica. La historiografía de los movimientos sociales y particularmente del movimiento obrero, obsesionada por sus planteamientos dialécticos y conflictivos, llega a despreciar la historia de la marginación. En un momento fundacional de la Asociación de Historia Social Española, en su primer Congreso celebrado en 1990 en Zaragoza $^{20}$, se despreciaba aún por parte de la mayoría de los historiadores sociales la historia de las tres "p", de presos, putas y pobres, como se dijo despectivamente en la sesión dedicada a la marginación. Se estimó que esta nueva orientación que se atrevía a introducir el tema de la pobreza y la beneficencia entre los asuntos propios de la historia social entonces dedicada al movimiento obrero era "algo impropio y alejado de los grandes vectores que debían conducir la historia de las masas en conflicto entre patronos y obreros, algo ajeno e insignificante comparado con el gran motor de la lucha de clases que movía la historia”. Producía rechazo, a pesar de que se trataba de una historia social de la pobreza elaborada en clave marxista, puesto que la mayor conquista historiográfica de los setenta consistió en descubrir el tratamiento de la pobreza como un instrumento de revolución burguesa en términos materialistas. Desde entonces, la historia social clásica hizo funcionar la asistencia como un mecanismo regulador del propio capitalismo y la pobreza como un contrapeso necesario al proceso de acumulación de riqueza capitalista.

Incluso cuando estos planteamientos del rígido materialismo se suavizaron con algunas propuestas más cualitativas, como la historia de las mentalidades, volvió a revisarse la asistencia desde arriba, desde la posición del asistente, fuera clasista o estatal. Se contemplaba en su dimensión de constructora de modelos sociales de clase y difusora de valores de grupos dirigentes, pero siempre subsistiendo la idea previa de que se trataba de una realidad subordinada de los grandes sistemas que ocupaban a la economía y la sociología clásicas. Había que presentar las políticas sociales como reflejos que proyectaban los miedos e intereses de los grupos dirigentes que las modelaban, había que insistir en que se configuraban a base de sus propios esquemas económicos. Simples medios para reforzar con

${ }^{20}$ CASTILLO, Santiago (coord.) - La Historia Social en España. Actualidad y perspectivas. Madrid, 1991. 
ello sus programas políticos, para hacer pedagogía social y educar a la sociedad en sus representaciones mentales, para afianzar sus sistemas de comportamiento o sus nuevos hábitos de trabajo y previsión. La segunda vuelta del materialismo histórico presentó la beneficencia como mecanismo de sumisión y dependencia, como práctica de estrategias de control, como emisión de mensajes de laboriosidad y sociabilidad. Trataba de demostrar cómo por medio de esa red institucional ambivalente, los asistentes por un lado estaban definiendo todo un proyecto social, consolidando su posición hegemónica en la sociedad, y cómo, por otra parte, trataban de imbuir en el pueblo menudo todo un esquema de valores propios, primero de los privilegiados del Antiguo Régimen, después de la burguesía oligárquica, y finalmente de las clases medias instaladas en el poder. De esa manera, se consideró la pobreza y su tratamiento asistencial como un medio para hacer la revolución de clase, como un instrumento de conformación de las burguesías locales, como una ocasión para consolidar las instituciones y servicios de la beneficencia municipal, como un anticipo y germen de los principales servicios de los ayuntamientos constitucionales ${ }^{21}$.

También la interdisciplinaridad obligó a los historiadores estructuralistas a mirar hacia otras ciencias o a otros géneros históricos y a fijarse en otros ámbitos temáticos afines. Conectaron con la historia urbana ${ }^{22}$, con la geografía y con la historia de la arquitectura y del urbanismo y pusieron de manifiesto el papel del equipo asistencial como generador de un determinado tipo de urbanismo burgués, como origen de los servicios municipales o de las instituciones locales. Se estudió la capacidad de la pobreza y la asistencia para crear y modular espacios urbanos y su influencia en la morfología de nuestras ciudades modernas y contemporáneas. Se decía, incluso, que no sólo había impactado en la materialidad de su construcción, sino sobre todo en la articulación de sus funciones urbanas y en la generación de una serie de servicios municipales urbanos, que hoy admitimos como espontáneos

${ }^{21}$ CARASA SOTO, Pedro - Los poderes municipales en relación con el Estado y el cambio social en Castilla, en Ayuntamiento, Estado y Sociedad. Los poderes municipales en la España Contemporánea. Valladolid: Ayuntamiento de Valladolid, Instituto de Historia "Simancas", 2000, p. 169-197.

${ }^{22}$ CARASA SOTO, Pedro - Por una historia social de la ciudad. Urbanización, pauperismo y asistencia, en BONAMUSA, Francesc; SERRALLONGA, Joan (ed) - La sociedad urbana, II Congreso de la Asociación de $H^{a}$ Contemporánea, Barcelona, 1994. 
y autónomos, y que, sin embargo, se debieron en su origen principalmente a instituciones de caridad y beneficencia. La ciudad había sido diseñada y articulada así en un importante porcentaje de funciones, servicios y morfología desde la caridad y la beneficencia: enseñanza, sanidad, higiene, orden público, abastecimientos, control del mercado laboral, sistema penal y represor, etc. habían sido influidos por las redes asistenciales.

$\mathrm{Y}$ otro tanto se dijo sobre el origen de muchas instituciones locales, mostrando cómo desde la actuación asistencial de los regidores de las ciudades comerciales del XVI, desde la racionalización ilustrada de las parroquias, desde la aparición del esquema municipal/provincial en las Cortes de Cádiz, se generalizó un esquema que configuraba a estas instituciones de gobierno local como impregnadas de una función asistencial, caritativa, represora o benéfica. Se consolidaba así el planteamiento institucional de la historia de la asistencia y la pobreza, el impacto que la caridad y la beneficencia habían producido en el proceso de formación de las instituciones locales españolas y en la determinación de sus funciones políticosociales. Seguíamos analizando el entorno de la pobreza y la asistencia, pero no su propia naturaleza y dinámica.

\section{La pobreza y la asistencia desde la perspectiva del sistema productivo o de la dialéctica social}

El primer principio aplicado a la interpretación de la pobreza y la asistencia fue el de la racionalidad de la economía clásica-patriarcal. Las ciencias de la economía y la historia económica, que se consolidaron en estos momentos históricos de socialización del pauperismo, fundamentaron sus visiones de la pobreza y la asistencia siempre desde la perspectiva de la racionalidad de la teoría clásica económica. Ya hemos mencionado la concepción del sujeto principal, que según la historia social clásica es el homo aeconomicus como prototipo de valores capitalistas y patriarcales, concepto básico que fue consolidado y establecido firmemente por las leyes de pobres o de beneficencia, en cuyo trasfondo subyace como presupuesto latente. La teoría clásica, centrada en los sistemas productivos, en los sujetos patriarcal, clasista y estatal, ha transferido a la historia social la manera de 
concebir la pobreza y la asistencia como meras consecuencias laterales de la dinámica interna de los sistemas generales ${ }^{23}$.

Este monopolio del sistema capitalista aplicado a la historia social no permitía ver otros aspectos informales, o incluso otros comportamientos económico-sociales básicos percibidos desde otras perspectivas. Hoy tratan de recuperarse con lo que se han llamado otras economías, como la economía informal que computa actividades no contabilizadas en el sistema teórico, como la economía social ${ }^{24}$ que descubre relaciones y dependencias impuestas por la sociedad, como la economía moral que valora influencias de valores éticos y de comportamientos humanos, como la economía de la sostenibilidad que detecta factores invisibles y callados indispensables para su mantenimiento. Como la economía de las microfinanzas ${ }^{25}$ capaz de poner en valor las aportaciones imperceptibles para las grandes magnitudes de los sistemas, capaces sin embargo de solucionar problemas que aquéllos no resolvían. Como la economía familiar o de la unidad doméstica que contemplan el funcionamiento de básicas unidades de gasto y producción que los sistemas dejaban pasar desapercibidas. Como la economía adaptativa, la economía de supervivencia, o la economía de la improvisación, sensibles para valorar fórmulas informales impuestas por la necesidad que producían soluciones más eficaces que las del sistema general. En definitiva, todas estas variaciones de economías alternativas, como la economía del cuidado, ven funcionar principios económicos no contemplados por los sistemas generales, pero que eran básicos en la supervivencia de la sociedad.

Incluso la historia institucional aplicada a la pobreza y la asistencia se había movido en un círculo muy limitado para comprender la riqueza de la

${ }^{23}$ CARASA SOTO, Pedro - La Historia y los pobres: De las bienaventuranzas a la marginación, Historia Social, 13 (1992) 77-99.

${ }^{24}$ SALINAS RAMOS, Francisco; HERRANZ DE LA CASA, José María - La economía social, instrumento de cohesión (2007): en la revista CIRIEC, $\mathrm{n}^{\circ} 55$ de 2006, que titula su número monográfico Economía Social y Desarrollo Rural, coordinado por SALINAS RAMOS, Francisco y HERRANZ DE LA CASA, José María.

${ }^{25}$ CARBONELL, Montserrat - Using Microcredit and Restructuring Households: Two Complementary Survival Strategies in Late Eighteenth Century Barcelone", International Review of Social History, 45, (2000) 71-92; CARBONELL, Montserrat - Second hand market and microcredit institutions in Barcelona, 18 ${ }^{\text {th }}$-19th centuries, in Colloque EUI Florence, Les circulations des objets d'occasion, 2002. 
actuación humana en su seno ${ }^{26}$. El análisis morfológico y administrativo de las instituciones asistenciales no ha sabido aprovechar la oportunidad que la red asistencial ofrece para descubrir en ella trasfondos importantes de la sociedad. A través de una institución analizada con perspectiva cultural se puede percibir cómo proyectan sus miedos e intereses los grupos dirigentes que las modelan, cómo ensayan en ellas soluciones económicas diferentes o complementarias con las del sistema, cómo refuerzan con las instituciones sus programas políticos, cómo proyectan sobre el resto de la sociedad sus representaciones mentales, sus sistemas de comportamiento, sus nuevos hábitos de trabajo y previsión, o cómo diseñan moldes de sumisión y dependencia, estrategias de control, mensajes de religiosidad y sociabilidad. La historia social clásica había perdido oportunidades de extraer toda la riqueza interpretativa de la pobreza y la beneficencia por la orientación de sus presupuestos propios de la teoría económica clásica o por los dictados impuestos por la teoría social materialista.

La segunda debilidad de esta historia social clásica ha sido historiar sistemas y no personas, agotar las relaciones sociales en dialécticas de clase y no buscar en ellas interacciones personales. Es verdad que esta tercera etapa estructuralista ha sido, sin duda, la más sólida y fructífera de la historiografía de la pobreza y la asistencia, pero sus estudios consideraron la pobreza y la asistencia, más que como una condición y actividad de la persona y de la sociedad, como un subproducto de un sistema económico o como un efecto espurio de una teoría social. Estos dos aspectos eran muy válidos y necesarios, su incorporación a la historiografía produjo un valioso avance y la permitió salir de un atasco institucional esterilizante, pero no llegó a agotar ni siquiera la mitad de la profunda y amplia dimensión histórica de las relaciones y significados de la pobreza y la asistencia. Su descarnada visión materialista dejaba en la penumbra las múltiples facetas más ricas y más sutiles de los pobres y los asistentes, no permitía acercarse a la cultura social de los pobres y los asistentes.

Se ha agotado la comprensión de la pobreza con excesiva sencillez en la contraposición capital/trabajo, patrono/asalariado, capitalismo/socialismo,

${ }^{26}$ CATAÑO, José Félix - Teoría económica y neoinstitucionalismo. Comentarios a "El neoinstitucionalismo como escuela". Revista de Economía Institucional, 5-9 (2003). 
burguesía/ proletariado, clases dirigentes/clases populares. Hoy vemos la insuficiencia y el reduccionismo de la perspectiva del conflicto entre clase obrera y capital aplicado a la pobreza. No hemos sabido ahondar en la relación interactiva y recíproca entre los pobres y los asistentes, en el mundo interior y en la vida cotidiana de los marginados, al dejarnos absorber por las reacciones unidireccionales que imponía el esquema mecánico ideológico del materialismo. Hemos podido descubrir sólo una pequeña parte de los efectos que se producen en el encuentro entre riqueza y pobreza en una determinada sociedad, y han quedado en la oscuridad otra buena parte, aun mayor, de las interacciones existentes entre los pobres y la sociedad, tal vez las más importantes.

Incluso podríamos ir más lejos, ni siquiera la contraposición riqueza/ /pobreza es la mejor perspectiva para llegar a conocer la realidad socio-cultural de los pobres y el significado de la asistencia. Tal vez la perspectiva colectivista, centrada en movimientos sociales y fenómenos masivos de pauperización, ha ocultado el papel relevante que han ejercido instituciones y élites que lideraron el sistema productivo y el orden social. Pero sobre todo ha ocultado la aportación que desde abajo generaba la estrategia de subsistencia familiar y personal al mantenimiento general. El conflicto absorbente no nos ha permitido ver dos culturas sociales diferentes, dos mundos imaginarios distantes, dos discursos sociales muy diversos, dos maneras alejadas de concebir lo económico y lo social, dos significados muy divergentes de lo que significa el poder en uno y otro lado. Al centrarnos en aquellos extremos que producían choque, hemos perdido los aspectos complementarios que enriquecían y diversificaban la relación social y económica. La historia social clásica padece una severa incapacidad para descubrir relaciones que no sean materiales, y probablemente los conflictos más significativos y decisivos que laten bajo la pobreza son de naturaleza inmaterial, los que privan del conocimiento, de la información, de la influencia, del prestigio, de las decisiones, de las redes sociales, de la autodefensa, de la elaboración de discursos influyentes.

El debate político dominante sobre la responsabilidad de los sistemas socio-económicos en la generación/solución de la pobreza también ha condicionado en exceso las macroconcepciones sistémicas de la historia social. La utilización de la pobreza como argumento político recriminador 
de un sistema contra otro ha representado una servidumbre que ha vinculado en exceso los planteamientos de la marginación y la política social a los presupuestos de los sistemas socio-económicos dominantes. El problema del pauperismo ha aparecido constantemente en el debate político ${ }^{27}$, visto como un factor de desequilibrio alarmante en las relaciones socioeconómicas de cada momento, tanto en el nivel de las relaciones internacionales de países pobres y ricos como en la escala interna de las crecientes diferencias entre los grupos sociales de los países desarrollados.

La costumbre ha consistido en culpar al sistema que se pretendía derribar de la generación creciente de pobreza y de incapacidad para resolverla. Desde la amenaza de la hecatombe malthusiana del crecimiento diferencial de recursos y población, en cada cambio histórico se ha imputado al sistema anterior el incremento de la pobreza. Así se tendió a concebir la pobreza como fruto inherente de un sistema viejo, y por el contrario, la mejor solución o política social era la del nuevo sistema que pretendía sustituirlo. La pobreza como arma política arrojadiza para justificar o deslegitimar los sistemas económicos o las organizaciones sociales nos ha obligado a comprenderla alternativamente como fruto de algún sistema. El capitalismo echó en cara este defecto al feudalismo, el socialismo se lo imputó al capitalismo como su gran fracaso, nuevamente el neoliberalismo se lo recrimina hoy al socialismo, y probablemente en el futuro se repetirá la acusación contra el actual Estado de Bienestar ${ }^{28}$. Particularmente, el materialismo ha insistido en explicar la pobreza como producto específico del capitalismo, y esto ha influido extraordinariamente en nuestra historiografia. Pero la tozuda realidad histórica confirma que la pobreza ha acompañado a todos los sistemas socio-económicos que se han sucedido, y por ello creemos que ese planteamiento superior no ayuda precisamente a su mejor conocimiento y explicación histórica.

Más allá de estas perspectivas generales, la pobreza no es sólo un desequilibrio material y productivo causado por un sistema determinado,

${ }^{27}$ SACHS, Juan - El fin de la pobreza. Cómo conseguirla en nuestro tiempo. Barcelona: 2003; BOLUFER PERUGA, Mónica - Entre historia social e historia cultural: la historiografía sobre pobreza y caridad en la época moderna. Historia Social, 43 (2002) 105-127.

${ }^{28}$ MUÑOZ DEL BUSTILLO, Rafael - El Estado de bienestar en el cambio de siglo. Madrid, 2000. 
sino que es más bien una situación socio-cultural presente en todos los sistemas. Su raíz es tan cultural como productiva, forma parte de la estructura jerárquica de todo poder económico y político, pero sobre todo pertenece al dominio social y cultural. La marginación se construye con códigos y significados elaborados por las élites y reelaborados por las sociabilidades de los pobres, comprende evidentemente carencias económicas, pero sobre todo implica inferioridades sociales, de prestigio, de información, de mentalidad, de redes sociales, etc. La naturaleza de la pobreza sólo se descubre tanto mejor en toda su profundidad y amplitud cuanto más se observe desde perspectivas inmateriales y culturales. Interesa verla como una realidad permanente e imprescindible, como contrarrealidad de todo poder, que subyace en los sistemas de representación jerárquica, en los organigramas de jerarquización social, en los presupuestos inherentes al ejercicio del poder político, en los códigos y significados de las relaciones sociales.

La cultura social sacralizada propia del mundo medieval y moderno presuponía que la pobreza era necesaria, siempre habrá pobres entre vosotros - decía Jesús, según el evangelista- tanto para que se salve el pobre ejerciendo la resignación cristiana como para que se salve el rico haciendo caridad. Y con una fuerte dosis de cinismo, sin apelaciones ya a lo sobrenatural, el liberalismo ${ }^{29}$ siguió defendiendo la pobreza como necesaria en la sociedad competitiva. Es una consecuencia natural del presupuesto de las diferentes capacidades individuales y de la inexorable competitividad darwiniana que acaban necesariamente produciendo desigualdad y marginación. La crítica socialista a este defecto inherente del liberalismo le condujo a la creencia utópica en una sociedad final sin clases ni diferencias, presuponiendo que el gobierno de los pobres culminaría con la desaparición de la pobreza, pero proyecto ha fracasado en su primera experiencia. El Estado de Bienestar, apoyado por los regímenes democráticos contemporáneos, se presentó como superador del problema de la desigualdad y la pobreza haciendo recaer en la capacidad fiscal del Estado la función de justicia redistributiva en forma

${ }^{29}$ CARASA SOTO, Pedro - Los peligros de la pobreza, los valores del liberalismo y las soluciones asistenciales burguesas, en VV.AA. - El siglo XIX en la España interior. Relaciones de poder y comportamientos políticos. Homenaje al Pfr. Artola, Madrid. 1996, p. 115-144. 
de servicios sociales para toda la sociedad. El Estado de Bienestar ${ }^{30}$ tuvo algunos notables avances al interior de los países desarrollados y ayudó a consolidar regímenes democráticos, pero está internamente en crisis y ha fracasado en la función global de reducir las diferencias entre países ricos y pobres. Al final, los que causan la pobreza y los que generan la asistencia no son los sistemas, sino la aplicación que de ellos realiza el hombre, es decir los factores culturales y humanos. De aquí que no deban estudiarse sólo como productos mecánicos de un sistema, han de ser considerados principalmente como efectos complejos de la voluntad humana.

Una de las más graves consecuencias de estos planteamientos materiales ha sido la deshumanización de la historia social. El aplastante dominio de las estructuras ha empequeñecido la figura humana en la historia hasta hacerla casi desaparecer, los marcos de grandes ámbitos espaciales en que se encuadraba, las largas duraciones temporales en que transcurría, las globalizadoras concepciones con que se interpretaba han acabado anulando al hombre como principal sujeto de la historia. El empeño actual pretende superar tal oscurecimiento de la figura humana y sacar al pobre a primer plano $^{31}$, más que el pauperismo interesan hoy los pobres, más que la pobreza cuantitativa importan ahora el ciclo vital y las relaciones del pobre. El materialismo produjo en España un interesante debate en torno a la conceptualización de la pobreza, sobre a los criterios y los umbrales de pauperización. Pero en dicha polémica apenas se fue más allá de la aplicación de elementos jurídicos y cuantitativos, faltó incorporar aspectos mentales, antropológicos, ambientales, de comportamiento, es decir, los más cualitativos y humanos.

${ }^{30}$ NAVARRO, Vicenç - El Estado del Bienestar en España. Madrid: Tecnos, 2004; RODRÍGUEZ CABRERO, Gregorio - El Estado del Bienestar en España: debates, desarrollos y retos. Madrid: Fundamentos, 2004; ADELANTADO, José (coord.) - Cambios en el Estado del Bienestar: políticas sociales y desigualdades en España. Barcelona: IcariaUAB, 2000; ALEMÁN, Carmen; FERNÁNDEZ, Tomás (coords.) - Política social y Estado del Bienestar. Valencia: Tirant lo Blanch, 2006; ALVARADO, Emilio (coord.) - Retos del Estado del Bienestar en España a finales de los noventa. Madrid: Tecnos, 1998.

${ }^{31}$ Cfr. la comunicación sobre "La deshumanización de la Historia", presentada por el autor al Segundo Congreso de la Asociación de Historia Contemporánea, Salamanca, 1999. 


\section{Los sujetos abstractos del discurso historiográfico clásico sobre la pobreza y la asistencia}

Los sujetos del discurso racionalista de la historia social clásica eran unas construcciones abstractas nacidas en determinadas teorías sociales y políticas. La historia de la pobreza y la asistencia en España ha sido enmarcada hasta ahora en las coordenadas historiográficas básicas y en los protagonistas abstractos del discurso racionalista de la modernidad. Según estos postulados, las únicas preguntas relevantes que cabía hacerse frente a la pobreza y la asistencia estaban siempre relacionadas con los sujetos dominantes de la vieja historiografía, los antiguos privilegiados de la Iglesia y la nobleza, la Corona, el Estado liberal y sus instituciones, las clases sociales dominantes, y las clases sociales dominadas del proletariado y el campesinado ${ }^{32}$. Además, todos estos sujetos eran entendidos como categorías homogéneas y dependientes del discurso central que explicaba todo proceso histórico como fruto de la acción racional de unas fuerzas económicas, políticas o culturales dominantes que pretendían conducir la historia en su propio provecho y en contra de los intereses de sus adversarios u oponentes. Todo se reducía así a las preguntas básicas de quién asiste, por qué asiste, cómo asiste, a quién asiste, creando un círculo cuyo centro era sólo el asistente, su identidad, sus razones, sus finalidades, sus modalidades. Este asistente coincidía siempre con el sujeto histórico protagonista en cada momento: la Corona y los privilegiados, la burguesía y las oligarquías, el Estado y sus profesionales. Todos los actores que no fueran esos protagonistas no contaban más que como complementos u objetos indirectos de la acción de dichos gestores principales. La dinámica de actuación de estos sujetos tenía siempre una teleología, regida por las teorías clásicas y racionalistas de la economía o la sociología, con una inexorable lógica interna en cada una. Se construía así un metarrelato histórico guiado por unas metas de progreso económico generado mecánicamente por la inapelable maquinaria de los intereses materiales como motores de la historia, por la inevitable dialéctica social de lucha de clases como dinamización histórica,

${ }^{32}$ CARASA, Pedro - Familia, Iglesia, Ayuntamiento y Estado en la Asistencia española. Revista de Historia Contemporánea, 25 (2008) 78-110. 
por la constante oligarquización del poder político mediatizado por esos motores socioeconómicos previos. En este escenario casi cerrado, no había un espacio para que se hicieran visibles y eficaces los factores culturales e ideológicos, o los aspectos informales y antropológicos, que siempre quedaban reducidos a meros elementos secundarios y subordinados a los primeros.

Había que presuponer siempre unos mecanismos casi automáticos de coherencia, de lógica de la acción dentro de unos axiomas previamente establecidos. Era la lógica interna del homo ceconomicus, guiado por los imperativos del máximo beneficio, el mínimo costo y la búsqueda de la dominación económica y social. Y cuando aparecía otro sujeto con otros principios era tildado de traidor a una clase, o de fracasado en su proyecto socio-económico o de pervertido por influencias extrañas de la superestructura.

Con este análisis no se percibían los pobres, sino sólo el pauperismo como amenaza al sistema, y tampoco se veían asistentes, sino la mera política de Estado y de clase. Lo que en el mundo feudal y tardo feudal era un sistema de salvación que combinaba pobres resignados con privilegiados caritativos, se ha convertido desde el siglo XIX en un pauperismo masivo amenazador para el orden social y la producción burguesa. La caridad salvadora del sistema sacralizado se mudó en política de control social del Estado o en autodefensa de los intereses de la clase burguesa. La identidad y la selección de los pobres venían marcadas por el riesgo de amenaza que representaban para el sistema económico o social. Por ello, los asistentes nunca eran personas, siempre eran instituciones - la Iglesia, el Estado, el Ayuntamiento - o clases sociales, las motivaciones del asistente eran siempre la defensa de intereses políticos o de clase, al margen de sus creencias, miedos o circunstancias personales. Y la asistencia se clasificaba sistemáticamente en dos categorías contrapuestas, la limosna particular y privada fruto de una actitud arcaica y retardataria, frente a la beneficencia pública como medio modernizador promovido por la clase dirigente. Y tras esta cuadrícula fija quedaba invisible toda la intensa vida económica y toda la compleja cultura social de las familias y personas populares que padecían necesidad.

La historia social clásica explicaba los recursos utilizados en la asistencia con la misma clave interpretativa del sistema general productivo y del ordenamiento social vigente, sencillamente como una reinversión de los asistentes en sistemas de autosalvación o de autoseguridad. Importaba 
mucho conocer si eran públicos o privados, si eran gestionados con la lógica de la historia económica clásica, si resultaban productivos en términos de rentabilidad social y económica. La medición de los umbrales de pobreza y la cuantificación de la misma se referían a las macromagnitudes del sistema general clásico, a su capacidad de interferir en los procesos productivos, laborales, fiscales. Eso importaba más que los niveles de necesidad existentes en la sociedad contemplada desde abajo, que las condiciones de vida cotidiana de los sujetos particulares y sus familias. Era tanta la penuria de términos y conceptos para entender estas realidades inmateriales y significativas de los pobres y los asistentes, que cuando torpemente nos acercábamos a ellas las expresábamos con locuciones propias de los sistemas, como "capital" simbólico, como "inversión” social, "renta” de prestigio. 